\title{
Prevalence and risk factors for bacterial vaginosis in sexually active females in age group 20-45 years and comparison of Amsel's criteria with Nugent's score
}

\author{
Sharadini Ghattargi ${ }^{1 *}$, Sheela N. ${ }^{2}$, Mary Dias $^{3}$
}

\begin{abstract}
${ }^{1}$ Department of Obstetrics and Gynecology, Vani-Vilas Hospital, BMC and RI, Bengaluru, Karnataka, India ${ }^{2}$ Department of Obstetrics and Gynecology, ${ }^{3}$ Department of Microbiology, St. John's National Academy of Health Sciences, Bangalore, Karnataka, India
\end{abstract}

Received: 15 July 2018

Revised: 06 August 2018

Accepted: 08 August 2018

\section{*Correspondence:}

Dr. Sharadini Naveen Kumar Ghattargi,

E-mail: sharadinicg@gmail.com

Copyright: (c) the author(s), publisher and licensee Medip Academy. This is an open-access article distributed under the terms of the Creative Commons Attribution Non-Commercial License, which permits unrestricted non-commercial use, distribution, and reproduction in any medium, provided the original work is properly cited.

\begin{abstract}
Background: In recent years Bacterial vaginosis has emerged as a global issue of concern due to its association with cervicitis, salphingitis, endometritis, postoperative infections, Urinary tract infections, pelvic inflammatory infections, spontaneous abortions, preterm delivery, abnormal Pap smears and increased susceptibility to HIV. Bacterial vaginosis is one of the most common lower genital tract infections among women of childbearing age and yet its diagnosis can be problematic. Gardnerella has been reported in upto $50 \%$ of women with no signs or symptoms of Bacterial vaginosis. So, it is important to know the prevalence and risk factors of Bacterial vaginosis, so that requirement of screening, early diagnosis and management can be planned.

Methods: After obtaining ethical committee approval, hundred consenting patients between 20-45 yrs of women, diagnosis by Amsel's criteria was done in gynaecology outpatient department and diagnosis by Nugent criteria was done in microbiology laboratory.

Results: In present study authors had a prevalence of $37 \%$ and among them $48.65 \%$ were asymptomatic. Bacterial vaginosis was statistically significantly associated with multipara and the trend was more towards low socioeconomic group and lower education. In our study we considered Nugent's criteria as gold standard and found that Amsel's criteria had positive predictive value $=88.88 \%$, negative predictive value $=79.67 \%$, sensitivity $=71.11 \%$ and specificity $=92.73 \%$.

Conclusions: Prevalence of bacterial vaginosis was 37\%, which is a significant proportion and therefore screening for bacterial vaginosis may be useful to detect and treat the cases, larger trials are required before any recommendation can be made.
\end{abstract}

Keywords: Amsel's criteria, Bacterial vaginosis, Nugent score, Prevalence, Risk factors

\section{INTRODUCTION}

About one fourth of women who attend the Gynaecology OPD complain of vaginal discharge (leucorrhoea) and vaginitis continues to be the most prevalent infection of the female genital tract. Leucorrhoea is a common gynaecological symptom causing annoyance as well as apprehension to the patients. ${ }^{1}$

The major causes of pathological discharge per vaginum are:

- $\quad$ Trichomonas vaginalis 
- Candida albicans

- Bacterial vaginosis

Bacterial vaginosis also called non-specific vaginitis, develops when the normally predominant hydrogen peroxide producing lactobacillus species in the vagina are replaced by mixed predominantly anaerobic flora, consisting of Gardnerella vaginalis, Mycoplasma hominis, Mobiluncus species, Bacteroides species, Prevotella species, Peptostreptococcus species, Fusobacterium species and porphyromonas species. ${ }^{2}$

Bacterial vaginosis is one of the most common lower genital tract infections among women of childbearing age and yet its diagnosis can be problematic. ${ }^{3}$ Bacterial vaginosis has been associated with behavioural, environmental or hormonal factors. ${ }^{4,5}$ Bacterial vaginosis is associated with cervicitis, salphingitis, endometritis, postoperative infections, Urinary tract infections, pelvic inflammatory infections, spontaneous abortions, preterm delivery, abnormal Pap smears and increased susceptibility to HIV. ${ }^{6}$ In recent years Bacterial vaginosis has emerged as a global issue of concern due to its association with ascending genital tract infections and with sexually transmitted diseases. ${ }^{7}$ So it is important to know the prevalence of Bacterial vaginosis so that proper management can be done. This study is done to establish the prevalence and risk factors of Bacterial vaginosis among sexually active reproductive age women, who attend gynaecology outpatient department in St. John's hospital. If the prevalence is significant, routine screening and treatment of Bacterial vaginosis in patients with abnormal vaginal discharge may help us to prevent the above mentioned obstetrics and gynaecological complications.

Objectives of present study was to estimate the prevalence of Bacterial vaginosis in sexually active reproductive females of age group 20-45 years, attending Gynaecology OPD in SJMCH, Bangalore and to identify the risk factors associated with Bacterial vaginosis.

\section{METHODS}

This Prospective observational study was conducted in the gynaecological outpatient clinic of the Department of Obstetrics and Gynaecology at St. John's Medical College Hospital, Bangalore. All ethical considerations and obligations were duly addressed. Duration of study was over a period of 1 year.

\section{Inclusion criteria}

All sexually active women of reproductive age group between 20-45 years who had come to Gynaecology OPD and those who gave consent for the study.

\section{Exclusion criteria}

Pregnant women as they form a different cohort.

\section{Diagnosis}

Sexually active females of age group 20-45yrs attending gynaecology OPD were selected, and the diagnosis of Bacterial vaginosis was determined based on Amesl's criteria and Nugent score. Diagnosis by Amsel's criteria was done in gynaecology outpatient department and diagnosis by Nugent criteria was done in microbiology laboratory. Demographic details of the women were entered.

\section{Amsel method}

It is a combined clinical and laboratory method in which Bacterial vaginosis was diagnosed if 3 or more of the following findings were present:

\section{Appearance of vaginal discharge}

Per speculum examination was performed, vulva was cleaned with a saline soaked swab, Sim's speculum was inserted into vagina without any lubricating or any antibacterial agents and type of discharge if any noted appearance of homogenous white, thin non-inflammatory vaginal discharge that adheres to the vaginal wall was diagnostic of Bacterial vaginosis.

\section{Vaginal fluid $\mathrm{pH}$}

Normal vaginal $\mathrm{pH}$ is $3.8-4.2$. $\mathrm{PH} \geq 4.5$ was taken as a high vaginal $\mathrm{pH}$ and it is seen in Bacterial vaginosis. Sample was obtained from the lateral vaginal wall or posterior fornix and tested with the help of narrow range pH paper

\section{Clue cells by wet mount preparation}

A swab containing vaginal fluid was obtained and immediately placed in $0.5 \mathrm{ml}$ of saline and examined under microscope for clue cells, which are vaginal epithelial cells with borders obscured with adherent small bacteria called "clue cells".

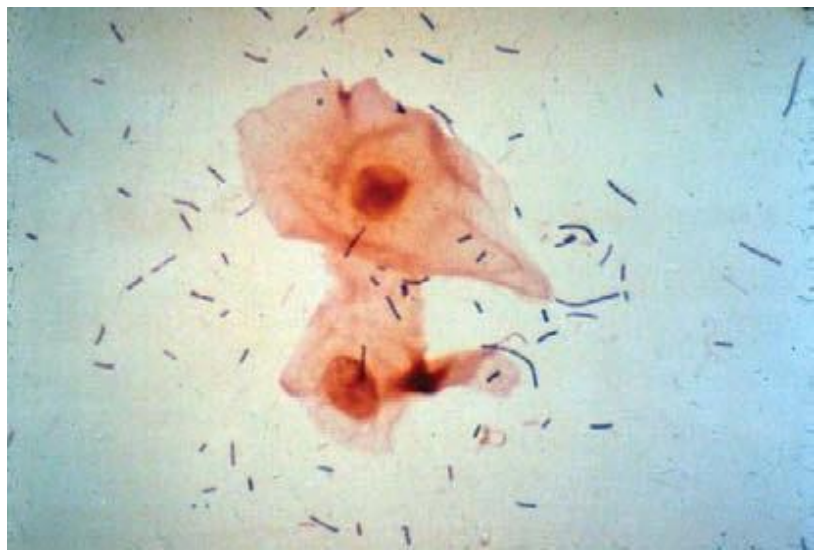

Figure 1: Clue cells. 


\section{Whiff test}

Adding a drop of $10 \% \mathrm{KOH}$ to vaginal fluid and sniffing the mixture. The test was interpreted as positive if a fishy aroma was noted.

\section{Nugent score}

Bacterial vaginosis was diagnosed by Nugent score after Gram stained smears was examined under microscope.

\section{Gram stain}

- Vaginal swab was taken from the lateral or posterior fornix, smear was made, air dried, heat fixed,

- $\quad$ Air dried, heat fixed smear was stained with methyl violet for one minute and washed under slow running water,

- Next Gram's iodine solution was poured and allowed to act for half to one minute,

- Smear was decolourised with acetone for 10 seconds and washed under slow running water,

- Counter staining was done with Safrannin for 20-30 seconds, washed under slow running water, dried and seen under microscope under oil immersion.

The Nugent method is a standardized point scoring system (0-10) based on the presence of 3 bacterial morphotypes: large Gram-positive rods (Lactobacillus spp), small Gram-negative or Gram-variable coccobacilli (Gardnerellaand anaerobic spp), and curved Gramvariable rods (Mobiluncusspp). Nugent score:

- $0-3=$ normal flora

- $4-6=$ intermediate flora

- $7-10=$ Bacterial vaginosis

\section{Diagnosing criteria}

Bacterial vaginosis was diagnosed if:

- Nugent score of 7-10 or

- Nugent score of 4-6 with 3 or more Amsel's criteria or

- If $\geq 3$ of the Amsel's criteria are positive.

\section{Statistical analysis}

Descriptive statistics reported as numbers and percentage for the categorical variable and chi-square test or fisher's exact test was done to test the association between the bacterial vaginosis positive and negative with demographical, clinical and laboratory variables, considering the Nugent criteria as gold standard was compared with the Amsel's criteria positive and negative, then specificity, sensitivity, PPV and NPV is calculated. Statistical analysis was done by using Statistical software STATA/IC version 12.1 and $\mathrm{p}<0.05$ is considered as statistically significant.
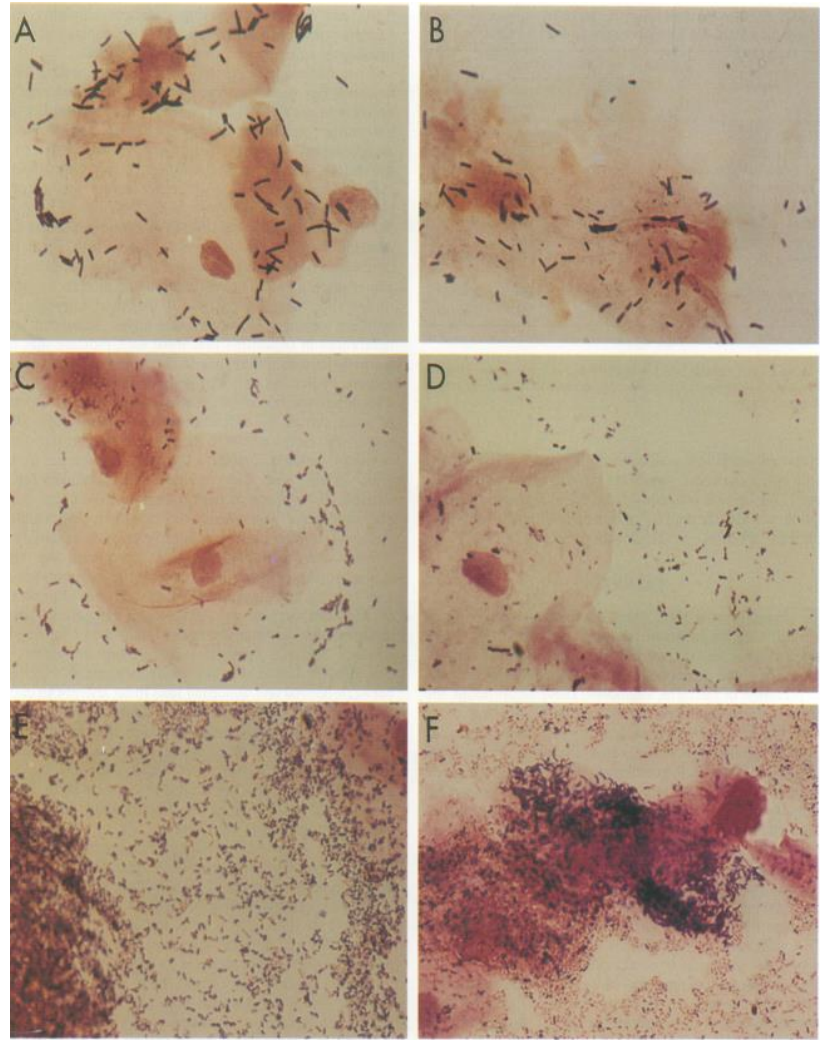

Figure 2: Gram-stained vaginal smears from women with normal vaginal flora (A and $B)$, intermediate vaginal flora $(C$ and $D)$ and bacterial vaginosis ( $\mathrm{E}$ and $\mathrm{F})$.

\section{RESULTS}

The study group comprised of 100 women in reproductive age group of $20-45$ years who attend the outpatient department of Obstetrics and Gynaecology at St. John's National Academy of Health Sciences, Bangalore.

\section{Prevalence of bacterial vaginosis}

Prevalence of bacterial vaginosis was found to be $37 \%$. Among 100 women, 37 were diagnosed with bacterial vaginosis.

\section{Risk factors}

Of the various socio-demographic risk factors assessed like-age, parity, socioeconomic status, education, religion, age at menarche, age of 1 st coitus, LMP, number of partners, new partner, OCPs, tubectomy, condom use, IUCD use, previous h/o discharge or treated for WDPV, we found in our study only multiparity was statistically significantly associated with bacterial vaginosis, but trend of bacterial vaginosis was seen for low education status, low socioeconomic status, LMP less than 17 days. OCPs and condom use were not found to be protective for bacterial vaginosis. 


\section{Descriptive statistics: risk factors}

Age distribution and bacterial vaginosis: Women with bacterial vaginosis were more in the age group of 20 years to 30 years.

Age of menarche and bacterial vaginosis: Age of menarche was not statistically significant

Parity and bacterial vaginosis: This was statistically significant. The women with Bacterial vaginosis were more in multiparous category about $59.46 \%$.

Socio-economic status and bacterial vaginosis: Statistically not significant, but trend shows that Bacterial vaginosis was found to be more in the lower socioeconomic group.

Education status and bacterial vaginosis: Bacterial vaginosis was more common in lower education profile women.

Age of $1^{\text {st }}$ coitus and bacterial vaginosis: Age of first coitus was not statistically significant.

LMP days and bacterial vaginosis: $62.16 \%$ of women with Bacterial vaginosis had LMP $\leq 17$ days.

WDPV and bacterial vaginosis: This was statistically not significant. About $51.35 \%$ with Bacterial vaginosis had vaginal discharge and $48.65 \%$ were asymptomatic.

Prior antibiotic use and bacterial vaginosis: Statistically not significant. $37 \%$ women with bacterial vaginosis had taken treatment for vaginal discharge.

Per speculum findings of cervix and bacterial vaginosis: Among women who were positive for bacterial vaginosis, $48.65 \%$ had healthy cervix, $45.95 \%$ had erosion and $5.4 \%$ had cervicitis.

Per speculum finding of vagina and bacterial vaginosis: Significant at $8 \%$ level. Women with bacterial vaginosis had healthy vagina in $75.68 \%$ and vaginitis in $24.32 \%$.

\section{A) Diagnosis of bacterial vaginosis by Amsel's criteria}

$\mathrm{pH}$ of $\geq 4.5$ is one of the criteria for diagnosis of bacterial vaginosis. Among 100 patients who were positive for bacterial vaginosis, $91.89 \%$ with bacterial vaginosis had $\mathrm{pH} \geq 4.5$ and $8.11 \%$ had $\mathrm{pH}$ of $<4.5$. Patients who were bacterial vaginosis negative $(17.46 \%)$ had $\mathrm{pH}$ of $\geq 4.5$.

Table 1: pH.

\begin{tabular}{|c|c|c|c|}
\hline & \multicolumn{2}{|c|}{ Outcome diagnosis } & \multirow{2}{*}{ p-value } \\
\hline & BV. negative & BV. positive & \\
\hline \multicolumn{4}{|l|}{ pH } \\
\hline$<4.5$ & $52(82.54)$ & $3(8.11)$ & \multirow{2}{*}{$<0.001$} \\
\hline$\geq 4.5$ & $11(17.46)$ & $34(91.89)$ & \\
\hline
\end{tabular}

Table 2: Type of discharge.

\begin{tabular}{|c|c|c|c|}
\hline & \multicolumn{2}{|c|}{ Outcome diagnosis } & \multirow[b]{2}{*}{$\begin{array}{l}\text { p- } \\
\text { value }\end{array}$} \\
\hline & $\begin{array}{l}\text { BV. } \\
\text { negative }\end{array}$ & $\begin{array}{l}\text { BV. } \\
\text { positive }\end{array}$ & \\
\hline \multicolumn{4}{|l|}{ Type of discharge } \\
\hline No discharge & $32(50.79)$ & $1(2.70)$ & \multirow{5}{*}{-} \\
\hline Homogenous & $12(19.05)$ & $30(81.08)$ & \\
\hline Curdy & $10(15.87)$ & $1(2.70)$ & \\
\hline Greenish and frothy & $3(4.76)$ & $0(0.00)$ & \\
\hline Mixed & $6(9.52)$ & $5(13.51)$ & \\
\hline
\end{tabular}

Among women with bacterial vaginosis, $81 \%$ had homogenous discharge, which was one of the diagnostic criteria for bacterial vaginosis.

$2.7 \%$ had no discharge, $13.51 \%$ had mixed discharge, $2.7 \%$ had curdy discharge and none had frothy greenish.

Table 3: Wet mount for clue cells.

\begin{tabular}{|lll|r|} 
& $\begin{array}{l}\text { Outcome diagnosis } \\
\text { BV. } \\
\text { negative }\end{array}$ & $\begin{array}{l}\text { BV. } \\
\text { positive }\end{array}$ & p-value \\
\hline Wet mount & & & \\
\cline { 1 - 3 } Negative & $62(98.41)$ & $7(18.92)$ & $<0.001$ \\
\hline Positive & $1(1.59)$ & $30(81.08)$ & \\
\hline
\end{tabular}

Wet mount which are vaginal epithelial cells with borders obscured with adherent small bacteria called "clue cells" was positive in $81.08 \%$ of women with bacterial vaginosis and was positive in $1.59 \%$ of patients who were negative for bacterial vaginosis. $18.92 \%$ had false negative.

Table 4: Whiff test.

\begin{tabular}{|lll|l|}
\hline & $\begin{array}{l}\text { Outcome diagnosis } \\
\text { BV. } \\
\text { negative }\end{array}$ & $\begin{array}{l}\text { BV. } \\
\text { positive }\end{array}$ & p-value \\
\cline { 1 - 2 } Whiff test & & & \\
\hline Negative & $59(93.65)$ & $3(8.11)$ & $<0.001$ \\
\hline positive & $4(6.35)$ & $34(91.89)$ & \\
\hline
\end{tabular}

Adding a drop of $10 \% \mathrm{KOH}$ to vaginal fluid and sniffing the mixture.

The test was interpreted as positive if a fishy aroma was noted. $91 \%$ of women with bacterial vaginosis had positive whiff test and $8.11 \%$ were false negative.

Table 5: Diagnosis by Amsel's criteria.

\begin{tabular}{|c|c|c|c|}
\hline & \multicolumn{2}{|c|}{ Outcome diagnosis } & \multirow[b]{2}{*}{ p-value } \\
\hline & $\begin{array}{l}\mathrm{BV} \text {. } \\
\text { negative }\end{array}$ & $\begin{array}{l}\text { BV. } \\
\text { positive }\end{array}$ & \\
\hline Amsel's criteria & & & \\
\hline Negative & $63(100.00)$ & $1(2.70)$ & $<0.001$ \\
\hline Positive & $0(0.00)$ & $36(97.30)$ & \\
\hline
\end{tabular}


Bacterial vaginosis was diagnosed if 3 or more of the following findings were present: $\mathrm{ph} \geq 4.5$, homogenous discharge, clue cells and Whiff test: $97.3 \%$ of women were diagnosed by Amsel's criteria and $2.70 \%$ were false negative.

\section{B) Diagnosis by Nugent's criteria}

Table 6: Diagnosis of bacterial by Nugent's criteria.

\begin{tabular}{|c|c|c|c|}
\hline & \multicolumn{2}{|c|}{ Outcome diagnosis } & \multirow[b]{2}{*}{ p-value } \\
\hline & $\begin{array}{l}\text { BV. } \\
\text { negative }\end{array}$ & $\begin{array}{l}\text { BV. } \\
\text { positive }\end{array}$ & \\
\hline \multicolumn{4}{|c|}{ Nugent score } \\
\hline $0-3$ & $51(80.95)$ & $4(10.81)$ & \multirow{3}{*}{$<0.001$} \\
\hline $4-6$ & $12(19.05)$ & $9(24.32)$ & \\
\hline $7-10$ & $0(0.00)$ & $24(64.86)$ & \\
\hline
\end{tabular}

The Nugent method is a scoring system (0-10) based on the presence of 3 bacterial morphotypes: large Grampositive rods (Lactobacillus spp), small Gram-negative or Gram-variable coccobacilli (Gardnerella and anaerobic spp), and curved Gram-variable rods (Mobiluncus spp). (Nugent score: $0-3=$ normal flora, 4-6 = intermediate flora, 7-10 = Bacterial vaginosis). Among 37 patients who were positive for bacterial vaginosis, $64.86 \%$ had a score of $7-10,24.32 \%$ had a score of $4-6$ and $10.81 \%$ had a score of $0-3$.

Table 7: Nugent's criteria.

\begin{tabular}{|c|c|c|c|}
\hline & \multicolumn{2}{|c|}{ Outcome diagnosis } & \multirow[b]{2}{*}{ p-value } \\
\hline & $\begin{array}{l}\text { BV. } \\
\text { negative }\end{array}$ & $\begin{array}{l}\text { BV. } \\
\text { positive }\end{array}$ & \\
\hline \multicolumn{4}{|c|}{ Nugent criteria } \\
\hline Negative & $63(100.00)$ & $13(35.14)$ & \multirow{2}{*}{$<0.001$} \\
\hline Positive & $0(0.00)$ & $24(64.86)$ & \\
\hline
\end{tabular}

Among women with bacterial positive, $64.86 \%$ had score of $7-10,24.32 \%$ had score of $4-6,10.8 \%$ had score of 0 3, 4 people who had Nugent score of $0-3$ were considered positive for bacterial vaginosis as they satisfied 3 of 4 Amsel's criteria.

\section{C) Comparison of Nugent's criteria and Amsel's criteria}

Table 8: Comparison of Nugent's criteria and Amsel's criteria.

\begin{tabular}{|llll|}
\multicolumn{4}{|c|}{ Pugent } \\
Positive & Negative & p-value \\
\hline \multicolumn{2}{|c|}{ Amsel's criteria } & & \\
\hline Positive & $32(71.11)$ & $4(7.27)$ & $<0.001$ \\
\hline Negative & $13(28.89)$ & $51(92.73)$ & \\
\hline
\end{tabular}

Nugent's criteria was considered as a gold standard for diagnosis of bacterial vaginosis in our study, when Amsei's criteria was compared with Nugent's criteria,
Amsel's criteria had a positive predictive value $=$ $88.88 \%$, negative predictive value $=79.67 \%$, sensitivity $=$ $71.11 \%$ and specificity $=92.73 \%$.

\section{DISCUSSION}

In present study we had $37 \%$ prevalence and among them $48.65 \%$ were asymptomatic.

Bradshaw et al studied 342 women, 157 (46\%) were diagnosed with bacterial vaginosis. It was associated with indicators of high sexual behaviour such as new sexual partner and greater number of male partners in the last year, increased number of lifetime sexual partners, less than 13 yrs of education, a past history of pregnancy and smoking $(<0.05)$. The mean age $( \pm$ standard deviation $)$ was 28.8 \pm 7.7 years. 138 had Nugent score 7-10, $125(91 \%)$ had Nugent score of 7-10 had 3 or more Amsel criteria, and 13 had less than 3 Amsel criteria but were considered positive for bacterial vaginosis in this study. 35 had Nugent score of 4-6, of whom 19 (54\%) had 3 or more Amsel criteria, and 16 had less than 3 Amsel criteria; these were considered negative. Use of oral contraceptive was negatively associated with bacterial vaginosis. There was association between bacterial vaginosis and being in the 1 st 17 days of menstrual cycle. $^{5}$

In present study, bacterial vaginosis was more common in the age group of 20 to 30 years. 24 had Nugent score of 7-10, among which $23(96 \%)$ had 3 or more Amsel's criteria and 1 had less than 3 Amsel's criteria but was considered positive. 21 had Nugent score of 4-6, among which $9(43 \%)$ had 3 or more Amsel's score and 12 had less than 3 Amsel's score; these were considered negative. use of OCP was not negatively associated with bacterial vaginosis. In present study $62.16 \%$ of women with bacterial vaginosis had LMP $\leq 17$ days.

Koumans et al found the prevalence of BV was $29.2 \%$ (95\% confidence interval $27.2 \%-31.3 \%$ ) corresponding to 21 million women with BV; only $15.7 \%$ of the women with BV reported vaginal symptoms. Prevalence was $51.4 \%$ among non-Hispanic blacks, $31.9 \%$ among Mexican Americans, and $23.2 \%$ among non-Hispanic whites ( $\mathrm{P}<0.01$ for each comparison). Although BV was also associated with poverty $(\mathrm{P}<0.01)$, smoking $(\mathrm{P}<0.05)$, increasing body mass index $\left(\chi^{2} \mathrm{P}<0.0001\right.$ for trend $)$, and having had a female sex partner $(\mathrm{P}<0.005)$, in the multivariate model, BV only remained positively associated with race/ethnicity, increasing lifetime sex partners $\left(\chi^{2} \mathrm{P}<0.001\right.$ for trend $)$, increasing douching frequency $\left(\chi^{2} \mathrm{P}\right.$ for trend $\left.<0.001\right)$, low educational attainment $(\mathrm{P}<0.01)$, and inversely associated with current use of oral contraceptive pills $(\mathrm{P}<0.005){ }^{6}$

In present study, we found that Bacterial vaginosis was statistically significant association with multiparous women. The trend was more towards low socio-economic 
group, lower education. All the women had only one partner.

Gilbert Donders in his review article found that in Caucasian women the prevalence was $5 \%$ to $15 \%$, in African and American blacks $45 \%$ to 55\%. In Asian women the prevalence was less well studied, but in general was around $20 \%$ to $30 \%$. About half of women with BV had symptoms. ${ }^{7}$ In present study we had a prevalence of $37 \%$ and among them $48.65 \%$ were asymptomatic.

Klebanoff et al noted among 2,888 women with bacterial vaginosis, $75 \%$ of women with and $82 \%$ of women without bacterial vaginosis never noted any vaginal odour in the past 6 months $(\mathrm{P}<0.001)$.

The corresponding values were $63 \%$ and $65 \%$ for never noting vaginal "wetness" ( $\mathrm{P}=0.02) ; 58 \%$ and $57 \%$ for vaginal discharge $(\mathrm{P}=0.65) ; 91 \%$ and $86 \%$ for irritation ( $\mathrm{P}=0.004) ; 88 \%$ and $85 \%$ for itching $(\mathrm{P}=0.64)$; and $96 \%$ and $94 \%$ for dysuria $(\mathrm{P}=0.002)$, respectively. Cumulatively, $58 \%$ of women with bacterial vaginosis noted odour, discharge, and/or wetness in the past 6 months compared with $57 \%$ of women without bacterial vaginosis $(\mathrm{P}=0.70)^{8}$

In present study among 37 women bacterial vaginosis, $46 \%$ with and $65 \%$ without bacterial vaginosis never noted any vaginal discharge in the past 6 months. Whereas $54 \%$ with and $35 \%$ without bacterial vaginosis had vaginal discharge in past 6 months.

Chaijareenont $\mathrm{K}$ et al, Considering Amsel's criteria as the gold standard, Nugent's score showed a sensitivity of $65.6 \%(95 \%$ CI $46.8 \%, 80.8 \%)$, specificity of $97.3 \%$ $(95 \%$ CI $93.5 \%, 99.0 \%)$, positive predictive value (PPV) of $80.8 \%$ (95\% CI $60.0 \%, 92.7 \%$ ), negative predictive value (NPV) of $94.2 \%(95 \%$ CI $89.7 \%, 96.9 \%)$ and accuracy of $92.6 \%$ (95\% CI $88.1 \%, 95.6 \%)$. Both vaginal $\mathrm{pH}$ and whiff test demonstrated $100 \%$ sensitivity.

However, vaginal $\mathrm{pH}$ showed lower specificity than the whiff test (58.9\% and $97.3 \%$ respectively) and concluded that, Nugent's score might not be suitable to use as a screening test for diagnosis of $\mathrm{BV}$ due to its low sensitivity. The whiff test was the best clinical criteria of Amsel's criterion in the diagnosis of $\mathrm{BV}$ due to its high sensitivity and specificity. ${ }^{9}$

In present study we considered Nugent's criteria as gold standard and found that Amsel's criteria had Positive predictive value $=88.88 \%$, Negative predictive value $=$ $79.67 \%$, Sensitivity $=71.11 \%$ and Specificity $=92.73 \%$

Smart $\mathrm{S}$ et al studied social and sexual risk factors for bacterial vaginosis. They studied 890 women with BV and 890 controls. women with BV were significantly less likely to have used hormonal contraception $(\mathrm{OR}=0.60$, 95\% CI: 0.51 to 0.81 ) or to have used condoms consistently $(\mathrm{OR}=0.5,95 \% \mathrm{CI}: 0.31$ to 0.71$)$ than controls. ${ }^{10}$

Sujatha $\mathrm{R}$ et al found among the 300 patients with symptomatic vaginal discharge, 123 (41\%) were diagnosed having bacterial vaginosis by Amsel criteria. Out of these $120(97.5 \%)$ patients had homogenous milk like discharge, $112(91 \%)$ had a positive whiff test, 121 $(98.3 \%)$ had clue cells and 111 [90\%] had $\mathrm{P}^{\mathrm{H}}>4.5$. and 126 [42\%] were diagnosed by gram stain. ${ }^{11}$

Eschenback et al compared the diagnosis of bacterial vaginosis on the basis of Amsel's criteria or presence of "clue" cells alone with Gram stain criteria and isolation of $G$. vaginalis on culture. They reported that if bacterial vaginosis defined by composite clinical criteria the independent diagnosis of bacterial vaginosis by Gram stain alone had a sensitive of $97 \%$ and a specificity of $79 \%$ and positive predictive value of $69 \% .^{12}$

B Adane in his article found overall prevalence rate of bacterial vaginosis by Gram-stain Nugent scoring criteria was $48.6 \%$, the proportion of bacterial vaginosis was the highest in age groups above 45 years. ${ }^{13}$

In present study, we found that bacterial vaginosis was statistically significantly associated with multipara. OCP and condoms were not found to be protective and also the prevalence of using OCP and condoms was less in our subjects. None of our subjects were smokers and none had multiple partners.

Mohammadzadeh $F$ et al studied the sensitivity, specificity, positive predictive value, negative predictive value, and accuracy of Amsel's criteria the results were $91 \%, 91 \%, 86 \%, 94 \%$, and $91 \%$, respectively. Moreover, the presence of clue cells in vaginal wet mount and whiff tests had the greatest sensitivity (97.6\%) and specificity (85.7\%), respectively. vaginal discharge had a sensitivity of $86.7 \%$ and a specificity of $56.5 \%$ in the diagnosis of $\mathrm{BV}$, vaginal $\mathrm{pH}$ had the lowest specificity $(46.6 \%)$. Various factors such as simultaneous infections of vagina and cervical mucus might had influenced the criterion. The study showed Amsel criteria to have high specificity $(91 \%)$ and sensitivity $(91 \%)$ in BVdiagnosis. And Amsel criteria could be as good as Nugent scoring system at diagnosing this infection. ${ }^{14}$

In present study authors considered Nugent's criteria as gold standard and found that Amsel's criteria had positive predictive value $=88.88 \%$, negative predictive value $=$ $79.67 \%$, sensitivity $=71.11 \%$ and specificity $=92.73 \%$.

\section{CONCLUSION}

Bacterial vaginosis is associated with cervicitis, salphingitis, endometritis, postoperative infections, Urinary tract infections, pelvic inflammatory diseases, spontaneous abortions, preterm delivery, abnormal Pap smears and increased susceptibility to HIV. 
Prevalence of BV among sexually active females in age group of 20-45 years attending outpatient department of OBG, St. John's medical college hospital was $37 \%$.

Risk factor associated with bacterial vaginosis which was statistically significant was multiparity. Bacterial vaginosis also showed trend towards low socioeconomic and low education status and LMP $\leq 17$ days. It was more common in age group of 20-30 years. Women using IUCD, OCP, Condom were less in present study

Prevalence of Bacterial vaginosis was $37 \%$, which is a significant proportion and therefore screening for bacterial vaginosis may be useful to detect and treat the cases. Amsel's criteria can be used to clinically diagnose Bacterial vaginosis especially in the out-patient department as it has good specificity. But since the sample size in present study was only 100, larger trials are needed before any recommendation can be made.

Funding: No funding sources

Conflict of interest: None declared

Ethical approval: The study was approved by the Institutional Ethics Committee

\section{REFERENCES}

1. Mc Gregor JA, French JI. Bacterial vaginosis in pregnancy. Obstetric Gynaecologic Survey. 2000;56(5):50-1.

2. Kaur KH, Puri KJPS, Anita M, Kiran B. Prevalence of Bacterial Vaginosis in sexually active females. J Obstet Gynecol Ind. 2003;53(2):178-80.

3. Sharon LH. Diagnostic microbiology of Bacterial Vaginosis. Am J Obstet Gynecol. 1993;169:455-9.

4. Nelson DB, Macones G. Bacterial vaginosis in pregnancy. Current findings and future directions. Epidemol Rev. 2002;24:102-8.

5. Bradshaw CS, Morton AN, Garland SM, Morris MB, Moss LM, Fairley CK. Higher-Risk behavioural practices associated with Bacterial vaginosis compared with vaginal candidiasis. Obstet Gynaecol. 2005;106(1):105-14.

6. Donders G. Diagnosis and management of bacterial vaginosis and other types of abnormal vaginal bacterial flora: A review. Obstetric Gynaecol Surv. 2010;65(7):462-73.

7. Koumans EH, Sternberg M, Bruce C, McQuillan G, Kendrick J, Sutton $M$ et al. The prevalence of bacterial vaginosis in the United States, 2001-2004; associations with symptoms, sexual behaviors, and reproductive health. Sex Transm Dis. 2007 Nov;34(11):864-9.

8. Klebanoff MA, Schwebke JR, Zhang J, Nansel TR, Yu KF, Andrews WW. Vulvovaginal symptoms in women with bacterial vaginosis. Obstet Gynecol. 2004 Aug;104(2):267-72.

9. Chaijareenont K, Sirimai K, Boriboonhirunsarn D, Kiriwat O. Accuracy of Nugent's score and each Amsel's criteria in the diagnosis of bacterial vaginosis. J Med Assoc Thai. 2004 Nov 1;87(11):1270-4.

10. Smart S, Singal A, Mindel A. Social and sexual risk factors for bacterial vaginosis. Sex Transm Infect. 2004;80:58-62.

11. Nawani M, Sujatha R, Halasuru NS. Diagnosis and prevalence of bacterial vaginosis in a teritiary care centre at Kanpur. J Evol Med Dental Sci. 2013 Jun 3;2(22):3959-63.

12. Eschenbach DA, Hillier S, Critchlow C, Stevens C, DeRouen T, Holmes KK. Diagnosis and clinical manifestations of bacterial vaginosis. Am J Obstet Gynecol. 1988;158:819-28.

13. Bitew A, Abebaw Y, Bekele D, Mihret A. Prevalence of bacterial vaginosis and associated risk factors among women complaining of genital tract infection. Int J Microbiol. 2017;2017.

14. Mohammadzadeh F, Dolatian M, Jorjani M, Majd HA. Diagnostic value of Amsel's clinical criteria for diagnosis of bacterial vaginosis. Glob J Health Sci. 2015 May;7(3):8-14.

Cite this article as: Ghattargi S, Sheela N, Dias M. Prevalence and risk factors for bacterial vaginosis in sexually active females in age group 20-45 years and comparison of Amsel's criteria with Nugent's score. Int J Reprod Contracept Obstet Gynecol 2018;7:3478-84. 